Proceedings

\title{
An Attempt to Optimise the Process of Nanofiltration of Pool Water Enriched with Compounds Associated with Secretions of the Human Body ${ }^{+}$
}

\author{
Edyta Łaskawiec*, Mariusz Dudziak and Joanna Wyczarska-Kokot \\ Institute of Water and Wastewater Engineering, Faculty of Energy and Environmental Engineering, \\ Silesian University of Technology, Konarskiego 18, 44-100 Gliwice, Poland; mariusz.dudziak@polsl.pl (M.D.); \\ joanna.wyczarska-kokot@polsl.pl (J.W.-K.) \\ * Correspondence: edyta.laskawiec@polsl.pl; Tel.: +48-32-237-16-98 \\ + Presented at Innovations-Sustainability-Modernity-Openness Conference (ISMO'19), Bialystok, Poland, \\ 22-23 May 2019.
}

Published: 14 June 2019

\begin{abstract}
This paper discusses the possibilities of purifying pool water by the process of nanofiltration. The analysis was carried out in the presence of substances analogous to the secretions of the human body. The samples of water collected from the school swimming pool was enriched with selected organic and inorganic compounds. The transport-separation properties of nanofiltration membranes were assessed. In the context of the removal of these organic compounds, the measurement of the total organic carbon concentration was of particular importance.
\end{abstract}

Keywords: swimming pool water; body fluids analogues; pressure driven membrane processes

\section{Introduction}

It is estimated that during one hour of physical activity one swimmer may excrete $50 \mathrm{~mL}$ of urine and $200 \mathrm{ml}$ of sweat, which results in the release into the water of many organic compounds whose structures comprise nitrogen, which quickly reacts with chlorine-based disinfectants [1]. The concentration and composition of disinfection by-product (DBP) precursors classified as body fluid analogues (BFAs) are strongly correlated with the number of swimmers, their hygiene habits, and the intended use of the pool. On the other hand, studies have confirmed the presence of urea, ammonia, uric acid, creatinine, creatine, lactic acid, citric acid, hippuric acid, chlorides, sulfphates, cations, and amino acids, e.g., histidine [2-4]. It has been confirmed that micropollutants in the form of DBPs produce various enzymes which cause oxidative stress in the cells of living organisms $[5,6]$. Numerous studies performed to assess the quality of swimming pool water using toxicological tests have confirmed the genotoxic, cytotoxic, and mutagenic properties of DBPs [5]. It is necessary to look for more and more effective ways to treat swimming pool water, which will make it possible to eliminate both the precursors and the products of their reactions with disinfectants. The work aimed to assess the possibility of using the nanofiltration process (NF) to remove impurities characteristic of pool water. The analysis was based on selected transport-separation properties of the commercial asymmetric membrane.

\section{Materials and Methods}

\subsection{Characteristics of BFA Model Solutions}

A solution of substances analogous to the secretions of the human body was prepared based on the selected data presented in the literature [2]. The reference substances (Sigma-Aldrich) were 
dissolved in demineralised water at $\mathrm{pH}=9.2 \pm 0.2$ (Table 1 ). The applied doses of the initial solution were determined by preliminary tests, based on the personal load of the selected pool facility and the capacity of the basin.

Table 1. Concentration of body fluid analogue (BFA) components in the tested solutions.

\begin{tabular}{cccc}
\hline & & \multicolumn{2}{c}{ BFA doses $(\mu \mathrm{L} / \mathrm{L})$} \\
Compounds of BFA & $\begin{array}{c}\text { Concentration in the Stock } \\
\text { Solution }{ }^{\mathbf{1}}(\mathbf{m g} / \mathrm{L})\end{array}$ & \begin{tabular}{c}
$\mathbf{1 5 . 6 0}$ \\
\cline { 3 - 3 } Solutions
\end{tabular} & $\begin{array}{c}\text { Concentration of the Component in the } \\
\text { BFA Solution }(\mathbf{m g} / \mathrm{L})\end{array}$ \\
\hline Urea & 14,800 & 0.2309 & 0.5506 \\
Ammonium chloride & 2000 & 0.0312 & 0.0744 \\
Creatinine & 1800 & 0.0281 & 0.0670 \\
Hippuric acid & 1710 & 0.0267 & 0.0636 \\
L-histidine & 1210 & 0.0189 & 0.0450 \\
Sodium phosphate dibasic & 4300 & 0.0671 & 0.1600 \\
Citric acid & 640 & 0.0100 & 0.0238 \\
Uric acid & 490 & 0.0076 & 0.0182 \\
\hline
\end{tabular}

${ }^{1} 25 \mathrm{~mL}$ of solution corresponds to the volume introduced by one bather during one $\mathrm{h}$ of physical activity.

\subsection{Analytical Procedures}

In the swimming pool water and feeds containing BFA doses, the concentration of total carbon (TC), organic (TOC) and dissolved (DOC) (after $0.45 \mu \mathrm{m}$ filtration, PVDF syringe filter) were determined using a TOC-L series analyser (Shimadzu). The ultraviolet absorbance was measured at a wavelength of $254 \mathrm{~nm}$ measured using the UV VIS Cecil 1000 (Analytik Jena AG: Jena, Germany). Turbidity was determined by a EUTECH Instruments model Turbidimeter TN-100. Measurement of the total and free chlorine concentrations in the pool water samples was made by the photometric method in cuvette tests using a VIS Spectroquant ${ }^{\circledR}$ Pharo 300 UV spectrophotometer (Merck: Darmstadt, Germany). Measurement of the $\mathrm{pH}$ and the redox potential of the pool water samples and feeds was carried out with a multi-parameter inoLab ${ }^{\circledR} 740$ meter (Poland, Wrocław, WTW, Measuring and Analytical Technical Equipment).

\subsection{Characteristics of Pool Water Samples}

Samples of pool water used in the research came from a basin with a capacity of $121.06 \mathrm{~m}^{3}$, intended for swimming. Two multilayer pressure filters (hydroanthracite - quartz sand) work in the pool water treatment circuit (contact coagulation + rapid filtration). The time of total exchange water in the basin is four $h$. The personal load of bathers on the day of collection was 15 people per hour. Table 2 presents the values of selected physicochemical parameters in pool water samples (BFA 1) and samples enriched with a solution of human sections (BFA 2 and BFA 3).

\subsection{Membrane Filtration Methods}

The study used flat nanofiltration membranes (polyamide-TFC) made by DowFilmtec ${ }^{\mathrm{TM}}$ (Sterlitech: Kent, WA, USA). The characteristics of the membranes and the operating parameters of the processes are given in Table 3 . The membranes were placed in a steel filtration cell with a volume of $380 \mathrm{~cm}^{3}$ where the active surface of the membrane was equal to $38.5 \mathrm{~cm}^{2}$. Before filtration started, new membranes were conditioned by filtering demineralised water to stabilise the volume of the permeate stream $\left(\mathrm{J}_{0}\right)$. The transmembrane pressure of all filtrations was $0.8 \mathrm{MPa}$. Each process was run continuously for $240 \mathrm{~min}$. After each cycle, the membrane was rinsed with demineralised water.

The intensity of the reduction of the hydraulic performance of the membrane was determined by a defined intermediate parameter-the relative volumetric permeate stream $\alpha(-)$, which is the quotient of the streams determined in the course of filtration of the treated solutions and demineralised water (membrane conditioning process), $\alpha=\frac{J_{0}}{J_{v}}$. This parameter is a measure of the disadvantageous phenomena accompanying membrane filtration, where $\mathrm{J}_{\mathrm{v}}$ is the volumetric flow 
rate of permeate $\left(\mathrm{m}^{3} / \mathrm{m}^{2} \cdot \mathrm{s}\right)$. In order to determine the separation properties of membranes, the rejection $\mathrm{R},(\%)$ was determined based on the reduction of the values of pollution indicators: $R=$ $\left(1-\frac{c_{p}}{c_{n}}\right) \cdot 100$, where $c_{p}$ is the concentration (indicator value) of pollutants in the permeate stream and $\mathrm{Cn}_{\mathrm{n}}$ is the concentration of contaminants in the feed $\left(\mathrm{mgC} / \mathrm{L}\right.$ or NTU or $\left.\mathrm{m}^{-1}\right)$.

Table 2. Selected physicochemical parameters of feeds for nanofiltration.

\begin{tabular}{cccc}
\hline \multirow{2}{*}{ Parameter } & \multicolumn{3}{c}{ Swimming Pool Water (feed) } \\
\cline { 2 - 4 } & BFA 1 $^{1}$ & BFA 2 $^{2}$ & BFA 3 $^{3}$ \\
\hline pH, (-) & 7.26 & 6.90 & 6.75 \\
Redox potential, $(\mathrm{mV})$ & 380 & 290 & 265 \\
Turbidity, $(\mathrm{NTU})$ & 0.81 & 1.20 & 1.30 \\
UV254, (-) & 5.90 & 7.80 & 9.60 \\
Free chlorine, $\left(\mathrm{mgCl}_{2} / \mathrm{L}\right)$ & 0.23 & 0.20 & 0.21 \\
Total chlorine, $\left(\mathrm{mgCl}_{2} / \mathrm{L}\right)$ & 1.31 & 1.36 & 1.41 \\
TOC, $(\mathrm{mgC} / \mathrm{L}))$ & 11.60 & 12.92 & 13.18 \\
DOC, $(\mathrm{mgC} / \mathrm{L})$ & 9.00 & 10.64 & 11.12 \\
TC, $(\mathrm{mgC} / \mathrm{L})$ & 19.41 & 21.63 & 22.19 \\
\hline
\end{tabular}

${ }^{1}$ samples of swimming pool; ${ }^{2}$ water from a swimming pool with a dose of $15.60 \mu \mathrm{L} / \mathrm{L}$ BFA solution;

${ }^{3}$ water from swimming pool with a dose of $37.20 \mu \mathrm{L} / \mathrm{L}$ BFA solution.

Table 3. Characteristics of membranes and operating parameters of the process.

\begin{tabular}{cccc}
\hline Feed & Membrane Symbol & MWCO, (Da) & Normalized Flux of Demineralized water $\mathbf{J}_{0} \cdot \mathbf{1 0}^{-\mathbf{6}},\left(\mathbf{m}^{3} / \mathbf{m}^{2} \cdot \mathbf{s}\right)$ \\
\hline BFA 1 & & & 6.85 \\
BFA 2 & YMNF903001 & $\sim 200-400$ & 6.93 \\
BFA 3 & & & 7.57 \\
\hline
\end{tabular}

\section{Results and Discussion}

The nanofiltration membranes were characterised by high separation capacities (Table 4). The average values of the retention coefficients for the pool water were: $83.55 \%$ for the TOC concentration, $76.39 \%$ for turbidity, and $80.30 \%$ for the absorbance of UV254.

Table 4. Values of parameters related to transport and separation properties of nanofiltration (NF) membranes.

\begin{tabular}{ccccccc}
\hline \multirow{2}{*}{ Filtration Time, (min) } & \multicolumn{3}{c}{ Relative Permeate Flux, $\boldsymbol{\alpha}(-)$} & \multicolumn{4}{c}{ Rejection of TOC, R (\%) } \\
\cline { 2 - 7 } & BFA 1 & BFA 2 & BFA 3 & BFA 1 & BFA 2 & BFA 3 \\
\hline 30 & 86.32 & 79.17 & 78.10 & 63.02 & 99.83 & 96.48 \\
60 & 84.21 & 79.17 & 76.19 & 88.72 & 92.42 & 82.97 \\
90 & 86.32 & 79.17 & 74.29 & 96.46 & 82.24 & 90.52 \\
120 & 84.21 & 79.17 & 72.38 & 92.48 & 77.00 & 83.39 \\
150 & 80.00 & 79.17 & 72.38 & 85.00 & 87.22 & 82.40 \\
180 & 84.21 & 79.17 & 70.48 & 87.70 & 81.52 & 80.92 \\
210 & 80.00 & 77.08 & 70.48 & 74.84 & 87.11 & 91.98 \\
240 & 75.79 & 72.92 & 66.67 & 80.16 & 78.40 & 92.78 \\
\hline
\end{tabular}

Higher values of coefficients were noted for solutions enriched with BFA compounds. For BFA 2, the average removal efficiency was: $85.72 \%$ (TOC), $86.67 \%$ (turbidity) and $97.28 \%$ (UV254). In turn for BFA 3, these were: $87.68 \%$ (TOC), 85.96\% (turbidity) and 100\% (UV254). On the other hand, the interesting relationship between the separation capacities of membranes and the concentration of the tested organic compounds.

With increasing filtration time, the transport capacity of all membranes has decreased. The highest reduction in the $\alpha$-value was noted for the samples of pool water feed enriched with a BFA $37.20 \mu \mathrm{L} / \mathrm{L}$ solution (Table 4). The increase in membrane separation capacities is probably directly related to the observed decrease in the quality of transport. Partial blocking of the pores of the 
membrane and reduction of the flowability of some of the compounds contributed to the increase in membrane separation abilities.

\section{Conclusions}

The nanofiltration process ensures a high degree of removal of low molecular weight contaminants from the pool water. The fundamental obstacle to using the process on a real scale is the process efficiency and phenomena associated with blocking the pores of the membrane and its degradation. This research will be developed to analyse the possibilities of optimising the nanofiltration process, following the optimised pre-treatment, optimal cleaning, and cleaning procedures. Modernisation of swimming pool water treatment circuits is necessary due to the need to improve water quality. It is necessary to implement solutions to reduce the water consumption of facilities and, moreover, also provide waste-free cleaning technologies. For these reasons, the research should be extended to thorough material analysis, including the design of a new type of membrane combining greater efficiency of the filtration process and high efficiency in removing low molecular by-products of disinfection.

Author Contributions: E.E. conceived and designed the experiments, performed the experiments and analysed the data under the supervision of M.D. M.D. contributed reagents, materials and analysis tools. E.E. wrote the paper under the supervision and review of J.W.-K. and M.D.

Acknowledgments: The work carried out as part of the faculty research grant for young scientists: "An attempt to optimize the process of nanofiltration in the presence of selected anthropogenic pollutants characteristic of swimming pool water." (Grant No. BKM-508/RIE-4/2018).

Conflicts of Interest: The authors declare no conflicts of interest.

\section{References}

1. De Laat, J.; Feng, W.; Adams Freyfer, D.; Dossier-Berne, F. Concentration levels of urea in swimming pool water and reactivity of chlorine with urea. Water Res. 2011, 45, 1139-1146.

2. Carter, R.A.A.; Joll, C.A. Occurrence and formation of disinfection by-products in the swimming pool environment: A critical review. J. Environ. Sci. 2017, 58, 19-50.

3. Chowdhury, S.; Alhooshani, K.; Karanfil, T. Disinfection by-products in swimming pool: Occurrences, implications and future needs. Water Res. 2014, 53, 68-109.

4. Kanan, A.; Karanfil, T. Formation of disinfection by-products in indoor swimming pool water: The contribution from filling water natural organic matter and swimmer body fluids. Water Res. 2010, 45, 926-932.

5. Yeh, R.Y.L.; Farre, M.J.; Stalter, D.; Tang, J.Y.M.; Molendijk, J.; Escher, B.I. Bioanalytical and chemical evaluation of disinfection by-products in swimming pool water. Water Res. 2014, 59, 172-184.

6. Farré, M.J.; Day, S.; Neale, P.A.; Stalter, D.; Tang, J.Y.M.; Escher, B.I. Bioanalytical and chemical assessment of the disinfection by-product formation potential: Role of organic matter. Water Res. 2013, 47, 5409-5421. 